\title{
The problem of theory and practice in the medical profession ${ }^{1}$
}

\author{
Jacques R. Kriel \\ Department of Internal Medicine \\ Medical University of Southern Africa \\ PRETORIA
}

\author{
Pieter van Veuren \\ Department of Philosophy \\ Rand Afrikaans University \\ JOHANNESBURG
}

\begin{abstract}
Scientific knowledge is a symbolic system consisting of hypotheses, models and theories generated by means of a paradigm-mediated interaction between a scientific community and a research domain. Such a knowledge generating paradigm consists of already existing theories, as well as methodological and ontological beliefs or assumptions. In this article it is argued that the meaning ascribed to the central concepts of medical science (such as patient, disease, causality and therapy) are fundamentally determined by the 19th century logical positivist scientific paradigm. The ontological and methodological implications of the posimodern natural sciences (e.g. quantum physics) have not been applied to medical science. The 19th century 'natural science paradigm' therefore acts as a metatheory for both medical science and medical practice. However, the theoretical knowledge system generated by medical science acts as the theory for the practice of scientific clinical medicine which therefore functions with the same understanding of the central concepts such as patient, disease and disease causality, therapy etc. The limitations of this paradigmatic monism are illustrated by an analysis of the medical and societal response to the AIDS epidemic and it is concluded that medical science and practice, because of the complexity of its research and practice domain, must accept in principle the possibility of paradigmatic pluralism (as in the social sciences) or should attempt to develop a holistic paradigm that will cope more adequately with its fields of research and practice.
\end{abstract}

\section{Introduction}

Scientific knowledge is a symbolic system generated by means of a paradigmmediated interaction between a researcher or research group and an aspect of reality (the research domain). The paradign consists of:

1 This essay is a condensed version of an MA Seminar Paper in Philosophy, submitted at RAU. (Supcrvisor: Dr. Picter van Veuren.) 
The problem of theory and practice in the medical profession

* the presently accepted theoretical beliefs of the research community regarding the research domain;

* their methodological beliefs regarding the appropriate methods that can access their research domain to provide valid knowledge (theories) of the domain, and

* their ontological assumptions regarding the domain structure. These ontological assumptions may be consciously propagated by the research community or may be implied by the research methodology without the research community necessarily being conscious of the implications (see Mouton \& Marais, 1988:125-151).

There is no possibility of a paradigm-free, direct access to 'reality'. The paradigm functions very much as a world view for its adherents in that it has a regulating function on their perception of the world. It becomes institutionalized in social institutions such as university research departments, scientific societies, scientific journals, industrial research organizations, etc. As an institutionalized scientific world view it influences decisions by the community regarding the problems that will be investigated, how they will be investigated and what type of solutions (i.e. 'theories') will be considered to be 'scientific', i.e. what that community will consider to be valid scientific knowledge.

The paradigm therefore also has a fundamental influence on research funding either by scientific institutions themselves, or, through the political influence of the institutions of science, by government and other societal funding agencies. Because 'scientific research' has become the accepted form of rationality in Western societies and the accepted basis for problem solving in all spheres, the scientific paradigm will have an influence and impact much wider than the scientific community.

The paradigm therefore has an influence not only on 'theoretical science' but also on its application in society by means of technology, professional practice, political decisions, etc. in so far as these claim to be based on 'scientific knowledge'.

In this essay I wish to explore the relationship between scientific knowledge and professional practice with specific reference to the medical profession. In order to do so I will

* give a short overview of the history of the natural science paradigm (natural science paradigm);

* explain what is meant by the natural science paradigm by setting out in broad outline the content of the ontological assumptions and the methodological beliefs; 
Jacques R. Kriel \& Pieter van Veuren

* explain how these assumptions and beliefs affected the central concepts of medical science, viz. that of patient, disease, disease causality and therapy;

* explain how the natural science paradigm and medical science have, through the specific content given to these concepts, affected medical practice and propose a model of the relationship between medical science (theory) and clinical medicine (practice);

* illustrate the argument with a case study of the medical and societal response to the AIDS epidemic within the context of the biomedical model

\subsection{From neo-Aristotelianism to the natural science paradigm: an historical overview}

A paradigm change involves changes not only in the theoretical beliefs ('knowledge') of a scientific community, but more importantly in the methodological beliefs and ontological assumptions. This is what happened during the Enlightenment when the neo-Aristotelian paradigm that dominated the intellectual life of the Middle Ages and formed the conceptual framework in terms of which theorizing took place about the natural world (physical, biological), as well as the social and spiritual (religious) aspects of life, was slowly replaced by what is now called the natural science paradigm.

In medical science this paradigm change was signaled by the replacement of the humoural theory of disease by the cellular theory of disease first comprehensively formulated by Virchov at the end of the 19th century.

Humoural pathology postulated that the human body was made up of four humours namely white bile, black bile, blood and phlegm. Health was a state of harmony between the humours and disease a wrong mixture of them. Therapy consisted of intervention to restore the balance. The theory was an application of the theory of the four elements (earth, water, air and fire) to the working of the body. The function and structure of the body was interpreted in terms of the wider cosmology - the body was a mirror (or microcosm) of the cosmos, the macrocosm. Verbrugh (1974:35) considers this theory to have been a major scientific achievement because a wide variety of phenomena could be understood and controlled within its framework. This theory served medicine from Greek times to the 17 th century.

According to the cellular theory of disease, disease is located in malfunctioning at the cellular level in one or more organs. This is the basic theory of disease with which scientific medicine still operates today

The major difference between the neo-Aristotelian and the modern explanatory strategies lies in their understanding of movement and of causality. For Aristo- 
The problem of theory and practice in the medical profession

telians the beginning of a process (the efficient cause) was not as significant for understanding the present configuration as was the final cause. The typically modern assumption is that something is explained once it can be explained in terms of initial conditions and forces and factors that interact according to natural laws. Something has been explained once it has been described as a mechanism.

Because of the explanatory and predictive power of the developing natural science paradigm it was applied to the biological or life world on the assumption that the structure of the life world was intrinsically the same as that of the physical world and that the general principles of the physical sciences were adequate to access this aspect of reality as well. This meant that both the physical and biological sciences began to operate with basically the same paradigm. Although it originated as a paradigm to explain the physical world, it now became a natural science paradigm. The natural sciences therefore became characterized by a paradigmatic monism.

The natural science paradigm came to be regarded as defining the essence of scientific rationality and even of rationality as such. Scientists therefore began to apply this paradigm to the developing human and social sciences as well.

However, during the first part of the 20th century the limitations of this natural science paradigm with regard to the human world became clear and several other paradigms were developed (e.g. phenomenology and hermeneutics) by different scientific communities working within the human sciences, thus establishing the paradigmatic pluralism presently characterizing the human sciences.

\subsubsection{Paradigmatic monism vs. paradigmatic pluralism}

If the paradigmatic monism of the natural sciences is taken as normative for scientific rationality, then the paradigmatic pluralism of the social sciences often leads to the conclusion that the social sciences are still in a pre-paradigmatic phase of development because of the fact that there is no discipline in which there is a single dominant paradigm.

Mouton and Marais (1988:150) argue that this conclusion is incorrect and is due to an application of Kuhn's paradigm concept out of context. Kulnn links the concept of a paradigm very strongly to that of problem solving which is the major epistemic goal in the natural but not in the social sciences. They suggest that the term paradigm should therefore be understood more in a metaphorical sense when applied to the social sciences. There is no reason in principle for demanding paradigmatic monism as a feature of scientific rationality. The present monism characterizing the natural sciences is the result of 'political activity' in the social institutions of science, and is not a requirement of 'scientific activity' as such. 
At the beginning of the 20th century, physics underwent a paradigm change in the development of quantum physics and its related sciences. Toulmin refers to the natural sciences that operate within the paradigmatic framework of quantum mechanics as 'postmodern sciences', while the natural sciences which operate within the Newtonian paradigm he calls 'modern sciences' (Foss \& Rothenberg, 1988:164).

The physical sciences therefore also essentially have a paradigmatic pluralism. Although the postmodern insights are beginning to be incorporated in the framework of thinking of the biological sciences, it has had little impact on medical science or practice. Systems theory seems to me to represent a possible alternative paradigm for the biological sciences. These developments have been set out diagrammatically in Figure 1.

Figure 1: Paradigm changes in the natural and human sciences

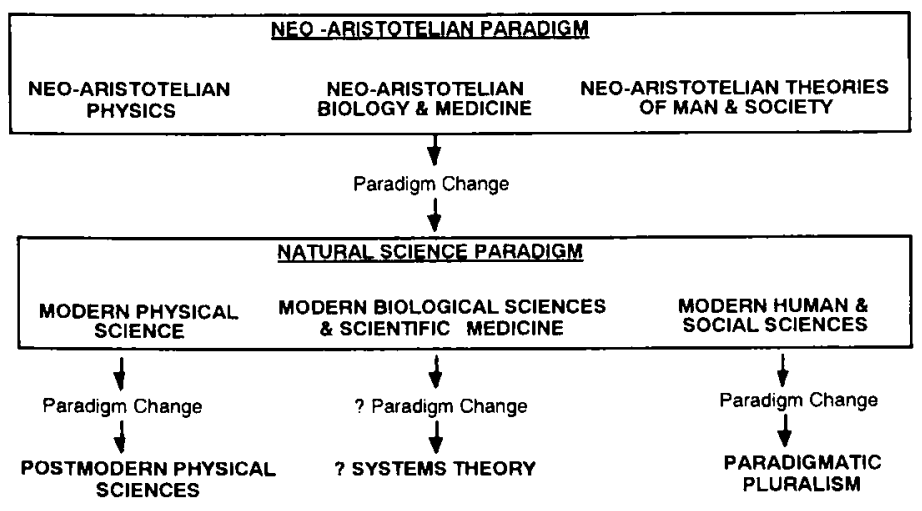

The gradual process by which medical science changed from the neo-Aristotelian humoural theory of disease to the modern cellular theory of disease, can be compared to the gradual change from the Ptolemaic cosmology to the Copernican heliocentric theory. Foss and Rothenberg (1988) refer to this change as medicine's first revolution. They suggest that medical science did not apply the implications of the quantum revolution in physics and that it therefore continues to operate within the 'modern paradigm'. They therefore explore the implications for medicine of what they call 'the theory of self-organising systems' (based on postmodern sciences) as an alternative paradigm referring to this as medicine's second revolution. The life sciences are therefore entering a situation of paradigmatic pluralism as well. The human sciences have thus actually been leading the way in that they have been exploring the possibilities inherent in paradigmatic pluralism since the first quarter of this century. 
The problem of theory and practice in the medical profession

It is now necessary to clarify the characteristics of the natural science paradigm and then to show how the acceptance of this paradigm by medicine affected the major concepts in medical science.

\section{The natural science paradigm}

As set out in section 1, a paradigm consists of:

* Methodological beliefs (directives by which to approach enquiry) and

* Ontological beliefs (directives by which to approach the world).

\subsection{Methodological beliefs}

The standard view of science has changed with time following its first tentative formulation in the work of Bacon. The Enlightenment ideal and understanding of science as a method of gaining knowledge of reality as it exists objectively, culminated in the logical positivism of the Wiener Kreis at the beginning of this century

Van Huysteen (1986:16) refers to logical positivistic as the first systematically formulated philosophy of science and states that it is still accepted by many scientists today. It definitely represents, I believe, the view of science held by most medical scientists and medical practitioners working in the RSA today. I believe that it also represents the view of science of the educated general public because it represents the underlying epistemology of the academic school curriculum and thus influences the view of scientific knowledge held by all school leavers.

The basic tenets of the logical positivistic view on scientific methodology can be explained in terms of the following concepts: empiricism, verification, the unity of science, objectivity and scientific method.

\subsubsection{Empiricism}

A basic postulate of the logical positivism is that all real knowledge is based on 'direct observation' which includes observation mediated through various forms of instrumentation (Van Huysteen, 1986:17). It postulates that theories can be based on theory free observation and that this enables an understanding of reality as it exists objectively i.e. independently of the human observer.

Sallie McFague (quoted by Van Huysteen, 1986:15) characterizes the logical positivism very succinctly as "... the assumption that it is possible to go directly from observation to theory without the critical use of models".

Logical positivism thus believes that it is possible to interact with a research domain directly on the basis of observation without the critical mediation of a para- 
digm. Methodological beliefs are considered to be self-evident truths abstracted from the practice of the most advanced of the physical sciences namely physics. These beliefs guide the practice of 'positivistic science' and thus fundamentally influence the type of theories that can be generated and will be recognized as valid.

These methodological beliefs imply corresponding beliefs regarding the ultimate structure of the research domain under investigation i.e. methodological beliefs imply ontological assumptions.

\subsubsection{Principle of verification}

In terms of the empiricist epistemological assumptions of the logical positivism, propositions are considered meaningful (i.e. scientific) only if it is possible to state which observations of reality could verify the proposition in question. In practice the only form of verification accepted by most natural scientists is observations that are quantifiable and that are expressible in the form of causal laws, i.e. only nomological explanations are considered verifiable and thus scientific. The ontological assumption accompanying these methodological beliefs is that reality is structured according to mechanistic principles expressible in terms of linear causality.

\subsubsection{Unity of science}

Implied in this empiricist view of knowledge is that all sciences (i.e. scientific disciplines or 'vakwetenskappe') must have the same epistemological structure. A further implication is that all scientific knowledge must (eventually) be translatable to the language of the physical sciences and to that of physics in particular (reductionism).

\subsubsection{Objectivity}

The term objectivity plays an important role in the thinking of natural scientists about their own practice. Within the logical positivistic conceptual framework, objectivity means knowledge obtained through the empirical method. It is thought to be free from any observer bias and a true (theory free) representation of reality. Because it is 'theory free observation', scientific findings cannot be influenced by personal or cultural beliefs and values.

Reality is therefore assumed to be directly accessible through the scientific method which gives objective knowledge which is value-free, free of observer bias and therefore impersonal, a-cultural, generally valid, universal and timeless. 


\subsubsection{Scientific method}

Scientific rationality is thus identified with a specific method. This method was so successful, that proceeding in accord with it came to be identified with proceeding in accord with the precepts of rational enquiry in general and theoretical science in particular (Foss \& Rothenberg, 1988:45).

Objectivity is guaranteed by the application of this specific method. Van Niekerk (1992:51) calls it "a stabilized procedure" which imposes a strict cognitive discipline on the researcher and legitimates it as 'scientific'.

The method delimits what type of questions can be asked and what types of answers can be given. The cognitive discipline ensures intersubjective validity. The method is used to generate scientific knowledge. It is also used in the process of verifying scientific theories. Important is the fact that the method is public, i.e. it is open to public scrutiny because it is known to and (potentially) repeatable by others.

Van Niekerk (1992:50-51) characterizes the method which came to epitomize 'scientific rationality', by the terms experimentation, inductive logic, verification and theory formation. I will now discuss each of these in turn.

\section{* Experimentation}

The stabilized procedure by which scientific knowledge is generated is said to start with the performance of strictly controlled, public and repeatable (stabilized) observations called experiments (Van Niekerk, 1992:50). By 'repeatable experiment' is really meant laboratory experiments under strictly controlled circumstances in which essential variables are limited to measurable ones. In the experiment the scientist is thought to be a detached observer who has no influence on the inexorable logic of the events unfolding before her (Foss \& Rothenberg 1988: 45).

\section{* Inductive logic}

These experiments 'establish the facts' on which the theories will be based through the application of the rules of inductive logic by means of which the particular judgments of observational language are developed into generalized hypothetical statements (Van Niekerk, 1992:51). Through the application of inductive logic the regularities brought to light during the experimentation are formulated in the form of generaliseable hypotheses.

\section{* Verification}

The next step is to try to prove that the provisionally formulated hypothesis is true. This is done by finding further experimentally controllable observations 
which will verify the claims of the hypothesis. (Popper's principle of falsification is not really a fundamental departure from the general approach.)

\section{* Theory formation}

Scientific theories are therefore considered to be constructed on the secure foundation of objective, value-free facts obtained by factual direct observation. If the testing (by verification or falsification) of the empirical generalizations are successful, a new scientific law has been established which can be integrated in a cumulative manner in the growth of scientific knowledge. In this manner all nonempirical discourse can be eliminated from scientific discourse. Van Niekerk (1992:53) summarizes this 'stabilized process' as follow's:

So groei die liggaam van wetenskaplike kennis deur die akkumulasie van ware feitelike en teoretiese oordele, dit wil sê van oordele wat op ' $n$ algemeen geldige wyse die objektiewe werklikheid met sekerheid ter sprake bring, en waarvan die waarheidsgehalte kontroleerbaar is deur die rekonstrueerbaarheid van die waarnemings waarop die teorie berus, sowel as van die logiese argumente wat die afleiding van hipoteses en teorie motiveer.

\subsection{Ontological assumptions}

The ontological assumptions and the methodological beliefs of a paradigm form a mutually interactive network. The methodological process must be directly related to the ontological reality that it is assumed to be able to access. To a certain extent, the (assumed) structure of the ontological reality is established (created) by the methodological beliefs and vice versa.

The ontological assumptions of the natural science paradigm obviously grew in sophistication over time. So e.g. the concept of a machine which underlies the mechanistic world view of the modem natural sciences, grew in sophistication as the sophistication of technology developed more and more complex machines.

The basic concepts under which I wish to describe the ontological assumptions of the natural science paradigm are: dualism, materialism, reductionism, linear (unidirectional) causality and determinism.

\subsubsection{Dualism}

Descartes' dualism was of fundamental importance in the development of science as it dichotomized the material and immaterial worlds, permitting the scientist to concentrate on aspects of nature more readily subject to experimentation and quantification (Foss \& Rothenberg, 1988:44). It thus formed (and in essence still forms) the essential background to empiricism. Gradually the emphasis shifted to the material aspects of reality so that the immaterial came to be seen as a derivative of the material. 


\subsubsection{Materialism}

The natural world, which is the domain of investigation of the natural sciences, is assumed to be a complex material whole, composed of assembled atomic parts which, when interacting with sufficient complexity, can form all the physical and biological systems that we encounter in the universe. This means that only fundamentally material explanations, i.e. explanations formulated in physicalist terms, will be considered as 'true' explanations.

Newtonian mechanics sanctioned the idea of organized complexity, such as found in biological systems, as in principle reducible to the interaction of its physical parts (Foss \& Rothenberg, 1988:24).

The world view implied by the natural science paradigm presupposes what Foss and Rothenberg (1988:52) call 'a single fundamental material level of reality'. Higher levels of organization do not involve ontologically new entities beyond the fundamental level elements of which the given entity is comprised. Primary status is thus conferred on matter and the material world and secondary or epiphenomenal status to the biological and mental worlds (Foss \& Rothenberg, 1988: 51). This leads to the following characteristic, namely that of reductionism.

\subsubsection{Reductionism}

Reductionism is a complex concept. It indicates, as mentioned above, that complex wholes exist only in terms of the interactions of their most fundamental parts. This has methodological implications as acceptable explanation now becomes the process by which a complex whole is analysed into its constituent parts and its behaviour explained in terms only of the interaction of those parts.

Reductionism thus implies that there is ideally a unified, physicalist language in whose vocabulary all events, physical, biological and mental are ultimately expressible. Only this type of explanatory discourse is thus legitimated by the natural science paradigm.

Reductionism and materialism are thus intimately linked in the natural science paradigm - life, the human being and culture are, in the last analysis transient events, by-products of physical organization because interacting physical particles governed by the laws of mechanics and thermodynamics are the ultimate stuff of the universe. As late as 1981 Hull (quoted by Foss \& Rothenberg, 1988:51) stated

Today, both scientists and philosophers take ontological reduction for granted. Vitalism is dead. Organisms are 'nothing but' atoms, and that is that 


\subsubsection{Unidirectional causality and determinism}

In the explanatory framework of the natural science paradigm, all events are explained in terms of antecedent events organized in causal chains and networks which are characterizable in terms of universal laws which make no reference to the causal efficaciousness of future events or higher levels of organization Therefore all explanations must be determinate explanations.

Because of the fixation on paradigmatic monism by the natural scientific community, this type of explanation was extended to biological and social phenomena. Contemporary medical reasoning in turn has borrowed its causal concepts from the other theoretical parts of science in accordance with currently accepted explanatory goals (Maull, quoted by Foss \& Rothenberg, 1988:55).

\section{The biomedical model}

Contemporary medical reasoning has not only borrowed its concept of causality from the natural sciences, but has, by identifying itself as a natural science, taken over the whole of the natural science paradigm. Like the practitioners of the social sciences, medical scientists and practitioners found themselves "standing in the shadow of the sciences as aspirants to some more perfect kind of knowledge which the natural sciences in particular represent" (Max Wartofsky, quoted by Foss \& Rothenberg, 1988:55)

The biomedical model is the model of medical science and medical practice which follows from the acceptance by medical science of the natural science paradigm. Because the term 'science' here specifically refers to the natural sciences, the term science of medicine could thus be defined as the symbolic knowledge system concerning the mechanisms, diagnosis, treatment or prevention of disease, developed according to the methodological directives and the ontological assumptions of the natural science paradigm.

By thus opting for a natural science framework as its only conceptual framework, biology in general and medicine in particular, gave up its autonomy to develop and employ sui generis modes of explanation, or for employing more than one explanatory framework as is possible within the human sciences

The commitment to the natural science paradigm commits the medical scientist to a view of the relevant research domain as one that is materialistic, deterministic, reductionistic and characterized by causal mechanisms, and the assumption that it is possible to exercise control through understanding the inherently predictable outcome of various actions. 
The problem of theory and practice in the medical profession

In addition, adopting the natural science methodological strategies commits the medical researcher to attach the same importance to conducting enquiry in a manner that is objective, a-cultural, a-temporal and impersonal in medicine as in physics or chemistry.

The biomedical model of medicine (or biomedicine) is thus the result of applying the natural science paradigm as the only paradigm for understanding the human being in health and disease. It locks medical science and medical practice into both a hierarchy of natural sciences and into the methodological constraints of the 'scientific method'.

\subsection{Central concepts of biomedicine}

The natural science paradigm thus has fundamental significance for the meaning attached to the central concepts of medicine namely that of patient, disease, disease causation and therapy. I will now discuss each of these in turn.

\section{* The patient}

The patient is understood as being essentially a biological organism which, in the words of Descartes, is "so built up and composed of nerves, muscles, veins, blood and skin, (that) though there were no mind in it at all, it would not cease to have the same functions" (quoted by Foss \& Rothenberg, 1988:24).

This is today still the basic model of the human being underlying the teaching of both the basic sciences and the clinical sciences as taught at medical schools in the Western world.

Descartes' dualism sanctioned the idea of the body as a machine that can be analysed independently of the mind and of the social and cultural context of the person. This means that the diagnostic process abstracts the patient from his or her concrete existence and assumes that "the patient, conceptualized as a biological organism, can be diagnosed in a context-free environment" (Foss \& Rothenberg, 1988:61). Cartesian dualism was later reduced to a monistic materialism in which the body became primary, and psychological functions became secondary epiphenomena of bodily processes. The psychological and social dimensions of human existence became irrelevant to the science and practice of medicine.

\section{* Disease and disease causation}

In biomedicine disease is conceptualized as something physically wrong in an organ or organs which can be described as a deviation from the nonn of measurable biological parameters (functional or structural). Disease is thus a material entity and can be completely described in physicalist language. Similarly the cau- 
Jacques $R$. Kriel \& Pieter van Veuren

ses of disease are physical factors: the presence of too much or too little of a critical substance or the presence of an intrinsically harmful agent.

Since disease is biology gone awry, and since the biological organism can best be understood by an understanding of its constituent parts and their physical interactions, there is no need to delve further than the physical mechanisms of disease. In this manner the ultimate level of explanation of disease becomes the level of molecular biology. To the extent that disease is strictly interpreted in physical terms, both research energies and research funding will be focused strictly in this direction

\section{* Therapy}

Against this background it is clear that therapy will also be conceptualized in purely physical terms as physical intervention (chemical, electrical or surgical) that will compensate for the surplus or deficiency of the critical substance or will neutralize the pathogenic agent.

From this analysis it is clear that the adoption of the natural science paradigm by medical science has had definitive consequences for the ascribable meanings of scientific medicine's central concepts.

\subsection{Institutionalized forms of medical science}

Although scientific medicine or biomedicine thus locates itself within the disciplinary matrix of the natural sciences, there is no specific scientific discipline called medicine which would be an equivalent to the disciplines of physics and chemistry in the physical sciences, or to botany and zoology in the biological sciences.

The scientific activities of scientific medicine take place within a large variety of separate disciplines which include the physical sciences (e.g. medical physics, medical biochemistry) and biological sciences e.g. microbiology, anatomy, physiology, pathology, genetics, immunology etc., as well as in the clinical disciplines, e.g. surgery, paediatrics etc. These clinical disciplines tend to refer to themselves as 'clinical sciences' especially within the academic environs of university faculties of medicine.

In spite of the fact that there are fundamental differences between the research methodologies as applied in the clinical situation (e.g. 'controlled repeatable experiments' are in principle not possible), clinical researchers see themselves essentially as 'natural scientists' applying the natural scientific empirical method. In actual fact their research process is much more closely allied to certain research processes used in the social sciences in which sophisticated statistical procedures have to be used in order to detect 'patterns of behaviour'. 
The research may be done within the context of academic departments in university faculties of medicine, or in industrial laboratories e.g. the pharmaceutical industry, but all these researchers would identify themselves as natural scientists and their work as exemplifying the methodological directives of the natural sciences. This is the basis of their claim to being 'scientific' Most of these disciplines are laboratory based and are often referred to as the basic sciences - i.e. basic to clinical medicine, which is seen as 'an applied science'.

The term medical science also includes scientific research done in clinical disciplines usually within the context of university hospitals related to medical schools. This research consists mainly in applying the theories and knowledge generated by basic science research to the clinical situation in order to test the validity or applicability in the clinical situation. However, such research may generate its own type of knowledge system especially regarding clinical manifestations, diagnostic methods and criteria, therapeutic regimes, risk factor identification, etc.

This research is usually done as an integral part of clinical practice (hence patient fears of being 'human guinea pigs'). Many clinical researchers have their own laboratories attached to their wards, or work in the laboratories of their basic science colleagues, while many 'basic scientists' are qualified medical practitioners. The distinction between basic science research and clinical research is therefore not clear cut, but both see themselves as 'natural scientists'.

Although the practice of clinical medicine involves persons, the research assumption of scientific medicine is that clinical research can be done as if the researcher is dealing with the same domain as is dealt with in the natural sciences.

Clinical researchers therefore go to extraordinary lengths to eliminate any reference to the human subject on which and by which the research is being done in order to obtain 'objectively valid' knowledge.

Such objectively valid knowledge is thought to be obtainable, e.g. by the use of the so-called placebo controlled double blind cross over therapeutic trials which attempt not only to eliminate researcher and patient bias, but also the so-called placebo effect i.e. the biological effect of interpersonal relationships and other non-physical factors

This methodology is used to compare the therapeutic efficacy of a new drug or therapeutic regime against that of the presently accepted regimes and/or against that of a 'placebo'. A placebo is a pharmacologically inactive substance which is administered as if it were a pharmacologically active agent. The 'placebo effect' measures the degree to which doctor-patient interaction affects the patients' response in terms of subjective feelings of well-being. This is especially impor- 
tant where the patients' responses are an important criterion for assessing the agent. The ideal is to dispense completely with patient responses and only to measure objective indicators of disease such as biochemical or histological changes. The assumption is that the body is a machine in which the 'personal domain' cannot affect the responses of the machine.

The concept of double blind means that neither the patient nor the doctor knows whether the patient is receiving the agent being tested or the placebo. Cross over refers to the fact that half way through the trial those patients who were on placebo start receiving the agent, and vice versa. Those researchers who know which agent is being administered to whom, do not come into contact with the patients at all.

Medical science is thus practised within the context of a large number of disciplines which are considered to fall within the ambit of the physical sciences, the biological sciences and the medical sciences. This scientific practice is guided by the natural science paradigm, which could thus be said to be the theory which guides the practice. The term theory used in this sense obviously means something different to 'theory' as a symbolic knowledge system generated by scientific activity. It is really a meta-theory.

We have now reached the point where we can analyse the relationship between theory and practice as it presents itself in the medical profession as well as the relationship between the natural science paradigm and the clinical practice of medicine.

\section{Scientific medical practice: the medical profession}

\subsection{Clinical practice as scientific practice}

Clinical medicine as a system of healing distinguishes itself from other systems of medicine on the basis that it, and it alone, is 'scientific'. Other systems of medicine such as homoeopathy, chiropractic, traditional medicine etc. are considered to be non-scientific, and therefore of no practical importance in health care.

The basis for the claim to being a scientific practice is twofold: Clinical practice is viewed as the direct application of 'scientific knowledge' (scientific being understood as natural science) and the clinical method is seen as resembling 'the scientific method'.

\section{* Clinical practice as the application of scientific knowledge}

Clinical practice is considered to be scientific because it applies the scientific knowledge (theories) generated by medical science in its varying institutional for- 
mats as set out in section 3. The term science is therefore understood as 'natural science' and the meaning given to the central terms of medicine namely disease, therapy, patient, etc. will be the same as in medical science.

Certain aspects of medical practice may be known to be based on very scanty or very doubtful 'scientific knowledge', but the ideal is to base clinical practice on 'sound scientific principles'. It is assumed that the domain of clinical practice is identical (or sufficiently identical) with the 'research domain' of 'medical science' (as described above) for this to be done. Clinical medicine is thus assumed to be a direct application of a body of (discipline based) natural scientific knowledge. Natural science (in the form of medical science) therefore supplies 'the theories', and clinical medicine applies them to patient care.

\section{* The clinical method represents the scientific method}

The interaction between the scientific doctor and the patient is regulated by a specific method known as 'the clinical method'. According to this method the doctor first systematically interrogates the patient regarding his or her symptoms (the subjective experiences of 'being ill' as well as other information regarding family history, work history, social habits that may have a bearing on the still-tobe-diagnosed disease). This process is known as 'history taking'. From this information the physician formulates a hypothesis regarding the possible disease or diseases that may cause the symptoms.

The history is followed by 'the physical examination' in order to find physical signs that will confirm or disconfirm the hypothesis. Physical signs are 'objective physical findings' e.g. enlargement of the liver, signs of anaemia, the presence of abnormal heart sounds, etc

This is usually followed by special investigations of e.g. the blood or urine, or Xray examination, etc. The aim is now finally to find objective evidence of disease, i.e. of abnormal physical processes. Without such objective evidence, there is no disease, regardless of the patient's story. In these cases the concepts of neurosis or psychosomatic complaints are invoked. The 'objective evidence' may be biochemical or anatomical (X-rays, biopsies), immunological, etc. The disease label is the one that best links together the history, the physical examination and the special investigation. This disease label is of vital importance, because it determines therapy. However, a disease is not simply a label, it is something that actually exists objectively.

From this description it can be seen that the clinical method presupposes the whole set of assumptions and beliefs that were described above as the biomedical model. 
The application of the clinical method through which a diagnosis is established and a decision regarding therapy is made in the case of an individual patient, is considered to be an exemplar of (natural) scientific rationality, and is e.g. likened to the 'scientific process' of data collection followed by hypothesis formulation and hypothesis testing.

The analytic process by which clinical information leads to the diagnosis is closely akin to the scientific method - the process whereby experimentation leads to the discovery of new knowledge (Harvey et al., 1984:2).

Although the actual position of Harvey et al. (1984) is much more nuanced than that suggested by this quotation, there are two assumptions operative under the surface of this model of clinical reasoning. The first is that 'the scientific method' is an analytical one and secondly, the assumption that the clinical reasoning process is (or can be) modeled on the 'scientific rationality' of the research process In this case too the term scientific is understood as natural science.

\subsection{The institutionalized forms of medical practice}

The medical profession is institutionalized as a large variety of clinical specialties such as surgery, paediatrics, internal medicine, obstetrics and gynaecology, family medicine, psychiatry, oncology and radiotherapy, etc. However, the laboratory specialties such as chemical pathology, virology, histopathology, medical microbiology, nuclear medicine, etc. as well as the community specialities such as community medicine and epidemiology, are considered to be part of scientific medical practice. Although aspects of the last two may be dealt with by "pure scientists' they are mostly practised by medical graduates

Each of these forms of practice has its own 'theory' in the sense that e.g. a psychiatrist would not be able to handle the practice of a surgeon - and by that I do not only refer to the specialized skills. The psychiatrist would be lost in the theory that informs the practice. But 'theory' here simply refers to the scientifically generated knowledge base which is applied in the clinical, laboratory or community practice.

But what then makes them examples of a common practice called medical practice?

* They all have a direct or indirect dealing with the phenomenon of disease diagnosis, treatment, prevention, rehabilitation. But this indicates that they must have a common concept of disease. 'Disease' is not a concept with a self-evident meaning, it obtains its meaning from a wider 'theory of disease'. This meaning is supplied by biomedicine. 
* Registration with the Medical and Dental Council. It is this registration in a specific category of practice that gives a medical practitioner the legal right to practise his or her specific branch of medicine.

* But this common registration is based upon a common education. All medical practitioners go through the same undergraduate education. Following this basic education a further period of specialization is required. It is success in the educational programme that allows registration. But the educational programme must be legitimated by the Council, so these two (education and registration) are really aspects of the same process. Only that which is taught at medical faculties is 'science' and only those who have undergone the social process of training and examinations at such faculties, may participate (Verbruch, 1974:46). But this educational process too presupposes the whole framework of biomedicine (Kriel \& Friedman, 1990).

\subsection{Theory and practice in the medical profession}

The theory for the practice of medicine is thus supplied by the science of medicine. This theory is the output of the enterprise of medical science which is a paradigmatic interaction between researchers and their research domain. The paradigm in question is the natural science paradigm.

The natural science paradigm as applied to medical science is called biomedicine. Biomedicine thus forms the meta-theory which regulates both the practice of medicine and the practice of medical education. Medical education thus reproduces the biomedical paradigm. These relationships can be set out diagrammatically as in figure 2 .

A final question needs to be addressed. What is the research domain of medical science?

Researchers approaching ostensibly the same reality from the perspective of different paradigms, 'see' different realities. The research domain is thus partly postulated or established or, at the very least structured, by the research paradigm.

So what is the research domain of medical science? Is it health, or is it the ill person, or is it biological deviations from the norm called diseases? From what was said above, it is clear that the research domain of biomedicine is specifically biological deviations from the norm. It is not the whole field of health and illness. 
Figure 2: The relationship between the natural science paradigm, scientific medicine, medical practice and medical education

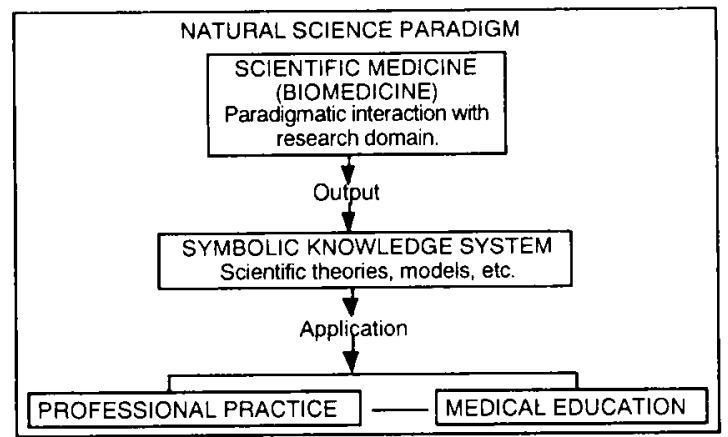

This has important implications because the medical profession projects itself as the sole societal interpreter of the field of health and illness while in fact its theories (which form the basis for medical practice) have a very limited application. Furthermore, its institutions guard the paradignatic monism of the natural science paradigm with all the scientific and political power at its disposal.

\subsection{Conclusion}

The standard view of medical science as a natural science which shares the ontological and methodological beliefs of the natural sciences as a group, thus fundamentally influences medical science and medical practice. Medical practice sees itself (in the form of the social institution of the medical profession) as applying the medical knowledge of medical science. The output of the research activity of medical science is a theoretical symbolic system which at the same time acts as the 'theory' for the 'practice of medicine'. The monistic paradigmatic framework of medical science, therefore also forms the paradignatic framework (or meta-theory) for medical practice

Schön (1987:1-40) has criticized what he calls the positivistic theory of practice which assumes that practice is nothing more than the application of 'scientific theories'. He points out that in professional practice the professional is not faced with clear cut problems as defined by the scientific paradigm, but by messy situations out of which a problem must be constructed. Basically this means that the 'research domain' of the natural sciences never is (or can be?) co-extensive with the reality within which practice takes place. If practice is approached 
The problem of theory and practice in the medical profession

solely from the perspective of the natural science paradigm, then a significant area of the real world is excluded from the interaction between the professional and her client.

\section{Biomedicine and the AIDS epidemic: a case study}

In this section I wish to illustrate very briefly the limitations of the biomedical model in dealing with the problem of the AIDS epidemic. I will focus mainly on the implications of the biomedical understanding of the cause of AIDS. For a more detailed discussion of the relationship between the biomedical point of view and AIDS, see Kriel (1991).

\subsection{The biomedical view of AIDS}

In line with the biomedical definition of disease, AIDS is seen exclusively as pathology in an organ system (the immune system) caused by a physical agent, the HI virus. All research efforts (and funding) are focused on finding a physical cure (e.g. a drug) or a physical form of prevention (e.g. a vaccine or promotion of condom use).

Sexual behaviour is seen as a risk factor - it is not seen as an essential aspect of the disease or of its causation. Very little attention is given to the nature of sexual relations as a human phenomenon. Sexuality, in turn, is interpreted as being simply a biological phenomenon explicable in terms of hormones and instinctual drives (whatever that means!). The social and cultural context (i.e. the human) context of sexuality is considered to be a private matter falling outside the scope of science. I contend that this biological model of sexuality not only distorts our understanding of human sexuality, but also that of animal sexuality.

This model of AIDS is not wrong, it is simply scientifically inadequate - using 'science' in its widest context as defined in the Introduction. But how does this inadequate model affect our approach to the epidemic? I will attempt to answer this question by focusing on the the aetiology (causation) of AIDS. I will argue that AIDS is not caused by the HI virus, but by the Hl virus within the context of a specific pattern of sexual behaviour that I will call 'open sexual relations'. Because the cause of the disease is not simply a physical factor, finding a physical cure or preventative strategy will therefore not break the epidemic. Finding a 'solution' to the epidemic requires a much more holistic approach than that offered by biomedicine.

\subsection{The cause of AIDS}

All sexually transmitted diseases (there are about 30 that afflict our species) have one characteristic in common, namely that they are dependent for their spread 
from person to person on the most intimate form of contact between two individuals of a species, namely sexual intercourse. The reason for this is that the causative organisms are very 'weak' organisms that are extremely sensitive to any exposure to the environment. Modern technology has made it possible for some of these organisms to spread from person to person through blood to blood contact, e.g. through the sharing of infected needles by intravenous drug users, or through infected blood transfusions. However, these methods are essentially 'transmission artifacts' that can initiate an infection, but cannot sustain an epidemic. I will now demonstrate that an epidemic of sexually transmitted diseases can only be maintained through the presence of a specific type of sexual behaviour within a community. Some sexually transmitted diseases, e.g. Hepatitis $\mathrm{B}$, can spread by other means as well, but AIDS is for all practical purposes an obligatory sexually transmitted disease i.e. it is entirely dependent on sexual transmission in order to initiate and maintain an epidemic.

\subsection{The cause of AIDS: behaviour as causation}

Both human and animal sexual behaviour is a very complex phenomenon. Most descriptive categories used for describing sexual behaviour have an ethical bias. Terms such as moral, immoral, promiscuous, fidelity etc. are, I believe, not useful in dealing with an empirical issue. Terms such as homo- or heterosexual, celibate, monogamy and polygamy are empirically descriptive terms for the structure of sexual relations and have been involved in the description of the causality of AIDS. So, e.g. AIDS was initially considered to be a 'homosexual disease'. It has now, however, become clear that AIDS has no essential relationship to homosexuality at all (see Saayman \& Kriel, 1992:22). In fact, the epidemic is decreasing in many homosexual communities but exploding in the heterosexual community. Are there other descriptive categories available?

In animal communities living under natural circumstances, sexually transmitted diseases are a very rare occurrence. Sexual behaviour in animal communities is usually described as 'free' or as 'promiscuous'. This is a complete misperception of animal sexuality. In nature sex is not only dangerous (many males lose their lives during the mating season and few survive without permanent scars!) but sexuality is very strictly controlled both hormonally and by species' specific mating behaviour patterns. Sex in nature is for gene selection, not for enjoyment!

The actual level of sexual activity is very low. Outside the mating season there is no sexual activity and males and females often live in separate communities while most of the mating season is spent on territorial delimitation and mate selection. But this alone cannot account for the low incidence of sexually transmitted diseases in nature. 
I would like to suggest that this phenomenon can be explained by the hypothesis that the function of species' specific mating behaviour is not simply gene selection, but the setting up of small temporary communities of closed sexual relations and that it is the presence of closed sexual relations that explains the absence of sexually transmitted diseases in nature.

If closed sexual relations do prevent the spread of sexually transmitted diseases, there would be sound evolutionary reasons why the procreational dynamics in nature should favour the establishment of closed sexual relations. The presence of sexually transmitted diseases in a natural community would decrease its procreational potential (e.g. through sterility and abortion) so that natural selection would favour those communities whose mating behaviour tended towards closed sexual behaviour patterns which exclude the possibility of sexually transmitted diseases.

The point of the argument is that a prerequisite for the existence of sexually transmitted diseases in a particular animal (or human) community is the presence of open sexual relations, because closed sexual relations make it impossible for any specific sexually transmitted disease to propagate itself in the community, and provides social immunity to the spread of the disease. So what is meant by closed sexual relations and how do they prevent the transmission of sexually transmitted diseases?

Figure 3: Examples of closed sexual relations: (i) Monogamous heterosexual (ii) Monogamous homosexual (iii) Polygamous (iv) Troop (v) Celibate

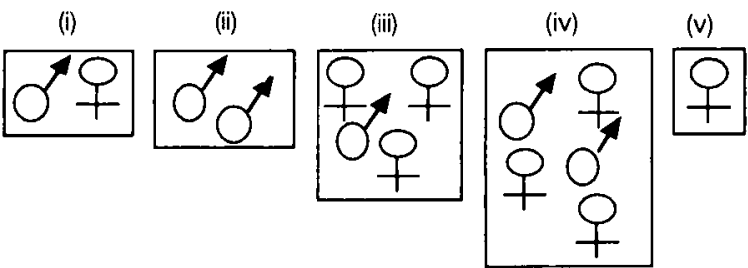

By a closed sexual relationship is meant a relationship in which sexual intercourse is limited strictly to the partners involved in the relationship. Such a closed sexual community may be structured along monogamous lines, or it may be polygamous (see Figure 3). It may be heterosexual or homosexual or celibate. The deciding factor is that the sexual partners remain absolutely loyal to one another, or remain celibate. Masturbation could therefore be seen as a form of closed sexual relations. 
The term open sexual relationship does not simply refer to multiple sexual partners, but where one of the partners in an otherwise stable relationship has sexual contact with a partner outside that relationship. A polygamous marriage is therefore not an open relationship. It only becomes so if one of the partners (male or female) has an 'outside relationship'. The sexual relations in animal troops, herds or other natural groupings (e.g. of chimpanzees), are often described as open because an oestrous female will mate with several of the males in the troop. However, the sexual relations are limited to that specific troop, and is thus 'closed'. It is an extended form of the human polygamous relationship.

In Figure 3 the boxes indicate that the infecting organism of any sexually transmitted diseases (including the HI virus in the case of AIDS) cannot enter into a closed relationship or, if it happens to have entered (e.g. via an infected blood transfusion), it cannot get out again into the community to initiate or maintain an epidemic. That is why it was stated earlier that transmission of the HI virus by blood transfusions and infected syringes or needles are 'transmission artifacts'. They may initiate an isolated infection, but cannot maintain an epidemic in any community in which closed sexual relationships are the norm.

Figure 4: Open hetero- and homosexual relations including a bisexual relationship. The open boxes indicate relatively permanent relationships.

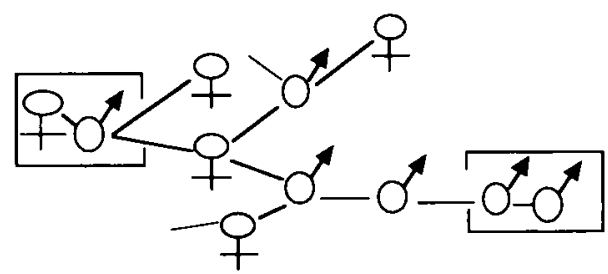

Figure 4 shows a situation of open heterosexual and homosexual relationships, including a bisexual relationship. From Figure 4 three conclusions can be drawn.

* One partner in many of these relationships could believe that he or she is involved in a closed relationship.

* AIDS has no intrinsic relationship to homosexuality. The crucial factor is not whether sexual relations are homo- or heterosexual, but whether they are closed or open.

* It shows that the HI virus can theoretically infect the whole community practising open sexual relations.

The minimum causal equation for the AIDS epidemic is therefore: the presence of the HI virus + open sexual relationships. 
The virus is therefore not the (only) pathogenic (disease causing) agent in the production of AIDS. It rather triggers action in something that is not a simple object (e.g. a body), but a pattern of relations, an integrated circuit or an ecological web of relationships. Only in combination with way-of-life factors affecting the host - in this case a way of life characterized by open sexual relations can the virus be said to cause the disease. It is therefore simply unscientific to maintain that the cause of AIDS is the HI virus. The only scientifically valid statement about the cause of AIDS is that it is caused by the HI virus in the presence of open sexual relations. (This principle is true not only of sexually transmitted diseases, but of many categories of disease.)

A community which practises closed sexual relations could be said to have social immunity against HIV infection. From this it is clear that the statement used in AIDS education campaigns 'Anyone can get AIDS' is simply not true, and is misinforming the public about the real causal relationships.

\subsection{On cures, vaccines and condoms}

By pleading that we must go beyond the biomedical view, I am not denying the importance of seeking a cure or vaccine, but even from a biomedical perspective, there are immense ethical, technical, cultural and economic problems facing researchers and health workers in developing these strategies. While we wait for biomedical research to deliver the goods the epidemic is escalating - and the most hopeful predictions talk about a decade or more before a 'breakthrough' can be expected.

But even if an effective and safe curative drug is discovered tomorrow, it will make no difference to the epidemic. It will of course make a difference to the survival of individual patients, but in terms of the epidemic it represents essentially a mopping up operation which does not affect the primary mechanism maintaining the epidemic, namely the sexual behaviour patterns of populations. It will be of benefit to the rich in the rich nations of the world, but for Africa it will be of very little benefit at all. Confirmation of this pessimistic view of the value of a curative drug is found in analysing the present worldwide epidemic of syphilis and other sexually transmitted diseases.

For syphilis and gonorrhoea a cheap and very effective 'miracle cure' is available in the form of penicillin, but the incidence graph for these diseases shows the same logarithmic increase as that of AIDS. This is understandable because these diseases are dependent on the same behaviour patterns for their transmission as the $\mathrm{Hl}$ virus. Therefore, unless we find a means of stopping transmission of the virus, discovery of a drug or other miracle cure will have no effect on the epidemic, especially in Africa, but also in other continents. 
And what about a vaccine? Because the HI virus is limited to man, the possibility is there for an effective vaccine to eliminate it from the earth as was done (so the virologists assure us) in the case of the smallpox virus. But I believe that the biological, social, cultural, economic and epidemiological context or ecology of the AIDS epidemic differs so vastly from that of smallpox, that the same biomedical strategies will not work.

Apart from the economic and ethical problems in developing, testing and implementing a vaccine, there is the problem of antigenic drift which enables the virus to change its antigenic structure against which the vaccine acts. The possibility of the virus changing its antigenic profile increases with the rate of transmission. Therefore, for a vaccine to be effectively deployed we need to decrease drastically the rate of transmission of the virus - which brings us right back into the field of human behaviour.

We are therefore in a classical Catch 22 situation: the biomedical strategies that are being proposed in order to break the epidemic (and millions of Rand are poured into research efforts to actualize them), all require the epidemic to be broken for them to become effective. However, the obvious point in the causal network at which the epidemic can be attacked, namely 'open sexual relations' is ignored (or is considered to be an interim measure until a 'medical breakthrough' is made) in policy planning as well as research funding.

This leaves condoms and programmes for promoting 'safer sex'. That condoms provide some protection against the transfer of the virus, is undeniable. But condoms leak and burst, and unless they are of very good quality (and thus very expensive) the virus can actually pass through the mesh. However, a much greater problem is the fact that the acceptance of the use of condoms depends on cultural factors that are specifically excluded by the biomedical model. Furthermore, the same attitudinal, social, cultural, economic and personal factors that underlie the open sexual behaviour patterns that maintain the epidemic, also militate against the use of condoms. Condoms form a vital part of the strategy, but again only in a situation in which the epidemic is under control - promoting condom usage will not bring the epidemic under control.

In homo sapiens the biological control of sexuality has disappeared. Sexuality is stimulated by the mind and the biological controls of sexuality have been replaced by social (cultural and religious) controls. These controls are by their very nature 'softer' control systems, and open sexual relations have probably been part of mankind's history since the very beginning. In Proverbs 5:15 large sections deal with the dangers of the adulteress and the wayward wife and the advice (to the males!) is: "Drink water from your own cisterns, running water from your own well." 
Human sexual behaviour is therefore more strongly influenced by socio-cultural and economic factors than by biological factors. Any breakdown in these spheres will also impact on sexual behaviour.

Although the major religions of Africa, as well as the major African cultural traditions, promote closed sexual relations, these controls were devastated by the impact of colonialism and the postcolonial wars. Western materialism and secularism with the attendant ethical and cultural relativism have taken their toll. Migrant labour, which has formed an integral part of apartheid but has also characterized labour practices in the rest of Africa as well as Europe, has devastated family life and made closed sexual relations for practical purposes impossible for large sections of the population. Religions cannot promote closed sexual relations without addressing these factors at the same time.

On the other hand there are cultural traditions that favour and support open sexual relations. These have equally to be addressed whether they are based in the liberal sexual ethic or in the ethos of patriarchal societies (Cullen, 1991).

We therefore need to go beyond negative approaches and seek to understand and address the root causes of open sexual relations. In fact, in spite of the near obsession with sexuality in the modern world, we have very little understanding of human sexuality except in terms of an (inadequate) biological model. We need to understand the essential nature of human sexuality. From this understanding we can then address and confront the problems of the relationship between sex and marriage, the problem of sexuality and the single person, masturbation as a form of sexual practice, the problem of sex education of teenagers etc. All of this will require a thorough understanding of sexuality as a specifically human phenomenon, its power and its controls. Various religions and cultural traditions will need to work together, because sexuality and AIDS know no cultural or religious boundaries.

\subsection{Conclusion}

Sexuality and AIDS are not phenomena that can be understood or managed purely as physical biological phenomena. The insight that closed sexual relations is an essential feature of sexuality in nature and open sexual relations an essential aspect of the causality of AIDS has two very important implications:

* We need to find ways of helping individuals and communities establish closed sexual relations as the norm. This will require, amongst others, intensive funding of research into factors contributing to open sexual relations and into the most effective ways and means of promoting closed sexual relations. At present, guided by the limited understanding of causality provi- 
ded by the biomedical paradigm, all the research funding goes into researching only one half of the causal equation.

The Christian community (in cooperation with other religious communities) has a vital role to play, but it will have to go far beyond the present negative and legalistic attitude towards sexuality. The Teacher of Proverbs $(5: 18-20)$ advises his sons: ".. may you rejoice in the wife of your youth. .. may her breasts satisfy you always, may you ever be captivated by her love". In the modern society with all its pressures towards sexual openness, this requires more from the community than pious good wishes or legalistic prescriptions.

* Religious communities are free to take up AIDS sufferers into a loving and caring community. There is no risk of infection to the community at all. In the light of the predicted pressure on the health services, religious communities will have to become involved in the home care of AIDS sufferers, and of the care of orphans.

At present, however, there is little indication that the Christian churches recognize the urgency of the situation or the vastness of the challenge before it.

\section{Bibliography}

CULLEN, T. ed. 1991. AIDS: A Christian Response. Balaka (Malawi) : Mountford Missionaries.

FOSS, L. \& ROTHENBERG, K. 1988. The Second Medical Revolution: From Biomedicine to Infomedicine. Boston : New Science Library.

HARVEY, A.M., JOHNS, R., McKUSIEK, V., OWENS, A. \& ROSS, R. eds. 1984. The Principles and Practice of Medicine. Norwalk: Appleton-Century-Croft

KRIEL, J.R. \& FRIEDMAN, M. 1990. Curricular Inertia: A Model to Explain the Failure of Curricular Reform in Medical Education. South African Journal of Higher Education, $4: 2$.

KRIEL, J.R. 1991. AIDS Is Not a (Medical) Disease. (In Van Niekerk, A ed. AIDS in Context: A South African Perspective. Cape Town : Lux Verbi. p. 37-56.)

MOUTON, J. \& MARAIS, H.C. 1988. Basic Concepts in the Methodology of the Social Sciences. Pretoria : Human Sciences Research Council.

SAAYMAN, W.A. \& KRIEL J.R. 1991. Towards a Christian Response to AIDS. Missionalia, 19:2.

SAAYMAN, W.A. \& KRIEL, J.R. 1992. AIDS: The Leprosy of Our Time? Towards a Christian Response to AIDS in Southern and Central Africa. Johannesburg: Orion.

SCHÖN, D.A. 1987. Educating the Reflective Practitioner. London: Jossey-Bass.

VAN HUYSSTEEN, W. 1986. Teologie as kritiese geloofsverantwoording: Teorievorming in die Sistematiese Teologie. Pretoria : RGN.

VAN NIEKERK, A. 1992. Rasionaliteit en relativisme: Op soek na 'n rasionaliteitsmodel vir die menswetenskappe Pretoria : RGN

VERBRUGH, H.S. 1974. Geneeskunde op doodspoor: Het gangbare medische mensmodel als voorwetenschappelijke ideologie. Rotterdam : Lemniscaat. 
